\title{
ANALISIS PENGARUH KOMPLEKSITAS TEKNOLOGI, INTERDEPENDENSI DAN DESAIN SISTEM INFORMASI AKUNTANSI TERHADAP KINERJA KARYAWAN PADA KOPERASI DI SURAKARTA
}

\author{
Endang Saryanti \\ endsary@gmail.com
}

\begin{abstract}
ABSTRAKSI
Tujuan penelitian ini adalah adanya pengaruh signifikan antara variabel kompleksitas teknologi, interdependensi dan desain Sistem Informasi Akuntansi terhadap kinerja karyawan pada koperasi di Surakarta.

Penelitian ini dilakukan dengan survai pada koperasi di Surakarta dengan responden karyawan bagian akuntansi. Jumlah sampel penelitian ini adalah sebanyak 36 orang. Sumber data primer dan sekunder. Metode pengumpulan data dengan kuesioner dan dokumentasi. Teknik analisis data dengan uji regresi linier berganda, uji F, uji t dan koefisien determinasi. Hasil penelitian diketahui persamaan regresi $\mathrm{Y}=12,625+0,414 \mathrm{X}_{1}+$ $0,454 \mathrm{X}_{2}+0,389 \mathrm{X}_{3}$, artinya masing-masing variabel kompleksitas teknologi, interdependensi dan desain SIA berpengaruh positif terhadap kinerja karyawan. Variabel yang paling tinggi pengaruhnya terhadap variabel kinerja karyawan adalah interdependensi karena memiliki nilai koefisien regresi paling tinggi. Dari uji $\mathrm{F}$ diketahu variabel kompleksitas teknologi, interdependensi dan desain SIA berpengaruh signifikan bersamasama dengan kinerja karyawan. Uji t diketahui kompleksitas teknologi, interdependensi dan desain SIA secara parsial berpengaruh signifikan terhadap kinerja karyawan. Koefisien determinasi diketahui bahwa kinerja karyawan bagian akuntansi dapat dijelaskan oleh variabel kompleksitas teknologi, interdependensi dan desain SIA sebesar 51,4\% sedangkan sisanya sebesar 48,6\% (100\% - 51,4\%) dipengaruhi variabel lain.

Kata kunci : Kompleksitas Teknologi, Interdependensi, Desain SIA dan Kinerja Karyawan.
\end{abstract}

\section{PENDAHULUAN}

\section{A. Latar Belakang Masalah}

Perubahan ekonomi secara global sekarang ini telah menuntut perusahaan untuk dapat mengembangkan perusahaan lebih maju lagi agar dapat bersaing dengan perusahaan lain. Perusahaan untuk mencapai tujuan yang diinginkan tentu saja akan memberdayakan seluruh elemen yang ada dalam perusahaan diantaranya adalah manajerlini atas, manajer lini bawah, karyawan bagian maupun pimpinan. Pencapaian tujuan perusahaan ditentukan oleh berbagai macam faktor dan kompleksitas teknologi menjadi salah satu yang mendukung kinerja perusahaan.

Teknologi pada awalnya dipandang sebagai alat untuk mendukung kegiatan operasi perusahaan dan membantu terciptanya efektivitas fungsi manajemen, dengan berbagai temuan baru dibidang teknologi informasi dan telekomunikasi. Kinerja perusahaan juga terkait dengan pemakaian teknologi, oleh karena itu kompleksitas teknologi yang diterapkan oleh perusahaan akan mampu memberikan dukungan pada kinerja perusahaan. Kompleksitas teknologi yang mendukung perusahaan maka dengan mudah perusahaan akan mampu untuk memperoleh informasi yang tentu saja untuk mendukung pembentukan sistem informasi perusahaan. Teknologi yang digunakan oleh perusahaan mau tidak mau akan memberikan dukungan penuh pada pembentukan sistem informasi perusahaan karena teknologi canggih yang diterapkan oleh perusahaan akan memudahkan untuk memperoleh informasi yang tepat, cepat dan akurat dimana nantinya akan terbentuk sistem informasi yang optimal.

Sistem informasi perusahaan yang digunakan dalam suatu perusahaan tentu saja sangat bervariasi yang terkait dengan sistem informasi manajemen dan juga sistem informasi akuntansi. Sistem informasi tersebut sama-sama 
memberikan dukungan optimal bagi kegiatan operasional perusahaan terutama terkait dengan desain Sistem Informasi yang dilandasi oleh kompleksitas teknologi yang akan menghasilkan struktur organisasi yang memiliki kecepatan respon terhadap perubahan kebutuhan konsumen.

Pelaksanaan operasional perusahaan mengubah sifat hubungan antara sub unit fungsional dalam perusahaan, karena aliran kerja antar sub unit akan sangat interdependensi (saling tergantung). Interdependensi ini menciptakan kebutuhan informasi tambahan untuk memastikan bahwa kerja yang mengalir ini dapat dikoordinasikan. Melalui interdependensi ini desain informasi sistem akuntansi akan lebih mudah dikembangkan perusahaan sekaligus bisa mendukung perkembangan perusahaan.

Perancangan desain Sistem Informasi Akuntansi akan didukung pula dengan teknologi yang ada. Kompleksitas teknologi merupakan banyaknya teknologi yang mendukung untuk dicapainya suatu desain Sistem Informasi Akuntansi yang lebih baik. Desain Sistem Informasi Akuntansi yang didukung oleh kompleksitas teknologi tentu akan mencapai kesempurnaan desain Sistem Informasi Akuntansi yang dihasilkan, hal itu tentu saja akan membuat desain Sistem Informasi Akuntansi itu juga semakin lengkap karena melalui teknologi yang ada akan membuat informasi yang diperoleh dapat diolah menjadi suatu informasi yang berguna bagi perusahaan.

Desain Sistem Informasi Akuntansi juga berkaitan dengan kondisi lingkungan perusahaan, dengan adanya perubahan lingkungan perusahaan akan mampu membuat desain Sistem Informasi Akuntansi yang telah disusun berubah. Ketidakpastian lingkungan perusahaan juga besar dalam memberikan sumbangan pada perubahan desain Sistem Informasi Akuntansi semakin sering lingkungan perusahaan berubah maka akan semakin sering pula desain Sistem Informasi Akuntansi juga akan berubah.

Faktor independensi, kompleksitas teknologi dan desain sistem informasi akuntansi akan dilakukan penelitian lebih lanjut terhadap pengaruhnya pada desain Sistem Informasi Akuntansi. Ketiga faktor tersebut melalui penelitian ini diharapkan akan dapat memberikan masukan mengenai peningkatan kinerja perusahaan dan itu bisa memberikan manfaat pada perusahaan. Penelitian ini dilakukan di koperasi sebagai salah satu organisasi kerja yang perlu mencapai peningkatan produktivitas kerjanya. Kinerja koperasi meningkat dan meningkatannya akan didukung oleh berbagai faktor seperti faktor independensi, kompleksitas teknologi dan desain Sistem Informasi Akuntansi.

Hal itu juga sesuai dengan penelitian dari Andreas Gandung E (2008) dengan penelitian mengenai pengaruh variabel customization, interdependensi, kompleksitas teknologi dan ketidakpastian lingkungan terhadap desain informasi SAM perusahaan advertising di Surakarta. Variabel customization, interdependensi, kompleksitas teknologi dan ketidakpastian lingkungan akan mempengaruhi desain informasi SAM perusahaan dan itu berbeda dengan penelitian ini dimana variabel dependennya peneliti memilih kinerja karyawan koperasi dan variabel desain Sistem Informasi Akuntansi menjadi vaiabel independent. penelitian ini akhirnya penulis beri judul " ANALISIS PENGARUH KOMPLEKSITAS TEKNOLOGI, INTERDEPENDENSI DAN DESAIN SISTEM INFORMASI AKUNTANSI TERHADAP KINERJA KARYAWAN PADA KOPERASI DI SURAKARTA".

\section{B. Perumusan Masalah}

Latar belakang masalah di atas dapat dipergunakan untuk merumuskan permasalahan sebagai berikut :

1. Apakah ada pengaruh signifikan secara parsial variabel kompleksitas teknologi, interdependensi dan desain Sistem Informasi Akuntansi terhadap kinerja karyawan pada koperasi di Surakarta?

2. Apakah ada pengaruh signifikan secara simultan variabel kompleksitas teknologi, interdependensi dan desain Sistem Informasi Akuntansi terhadap kinerja karyawan pada koperasi di Surakarta? 


\section{Tujuan Penelitian}

Setiap penelitian yang dilakukan pasti memiliki tujuan, begitu pula dengan penelitian ini. Tujuan dalam penelitian ini memberikan bukti empiris bahwa :

1. Ada pengaruh signifikan secara parsial variabel kompleksitas teknologi, interdependensi dan desain Sistem Informasi Akuntansi terhadap kinerja karyawan pada koperasi di Surakarta.

2. Ada pengaruh signifikan secara simultan variabel kompleksitas teknologi, interdependensi dan desain Sistem Informasi Akuntansi terhadap kinerja karyawan pada koperasi di Surakarta.

\section{ANALISA DATA DAN PEMBAHASAN}

\section{A. Data Penelitian}

PENYEBARAN KUESIONER

\begin{tabular}{|c|l|c|c|c|c|}
\hline No & \multicolumn{1}{|c|}{ Alamat KAP } & $\begin{array}{c}\text { Angket } \\
\text { disebar }\end{array}$ & $\begin{array}{c}\text { Angket } \\
\text { kembali }\end{array}$ & $\begin{array}{c}\text { Angket } \\
\text { rusak }\end{array}$ & $\begin{array}{c}\text { Angket } \\
\text { terpakai } \\
\text { sebagai } \\
\text { sampel }\end{array}$ \\
\hline 1 & Koperasi Tiga Jaya Mandiri & 3 & 3 & - & 3 \\
\hline 2 & Primkopti Surakarta & 4 & 4 & - & 4 \\
\hline 3 & Koperasi Pandawa Jaya Surakarta & 3 & 3 & - & 3 \\
\hline 4 & KPRI Asih Surakarta & 4 & 4 & - & 4 \\
\hline 5 & Koperasi Mekar Jaya & 4 & 4 & - & 3 \\
\hline 6 & Koperasi Dana Sakti & 5 & 5 & 1 & 4 \\
\hline 7 & Koperasi Ikhlas & 3 & 3 & - & 4 \\
\hline 8 & KPRI STM N 1 Surakarta & 3 & 3 & - & 3 \\
\hline 9 & Koperasi LPTD & 5 & 5 & 1 & 4 \\
\hline 10 & KPRI SMKN 4 Surakarta & 4 & 4 & - & 4 \\
\hline Jumlah & 38 & 38 & 2 & 36 \\
\hline
\end{tabular}

Sumber : Data Primer

\section{B. Pengujian Instrumen}

1. Uji validitas

a. Variabel kompleksitas teknologi $\left(\mathrm{X}_{1}\right)$

HASIL UJI VALIDITAS VARIABEL $\mathrm{X}_{1}$

\begin{tabular}{|ccccc|}
\hline Item soal & $\alpha$ & $\mathrm{r}_{\text {hitung }}$ & $\mathrm{r}_{\text {tabel }}$ & Keterangan \\
\hline 1 & 0,05 & 0,545 & 0,329 & Valid \\
2 & 0,05 & 0,560 & 0,329 & Valid \\
3 & 0,05 & 0,652 & 0,329 & Valid \\
4 & 0,05 & 0,63 & 0,329 & Valid \\
5 & 0,05 & 0,358 & 0,329 & Valid \\
6 & 0,05 & 0,453 & 0,329 & Valid \\
\hline
\end{tabular}


b. Variabel Interdependensi $\left(\mathrm{X}_{2}\right)$

HASIL UJI VALIDITAS VARIABEL $\mathrm{X}_{2}$

\begin{tabular}{|c|c|c|c|l|}
\hline Item soal & $\alpha$ & $\mathrm{r}_{\text {hitung }}$ & $\mathrm{r}_{\text {tabel }}$ & Keterangan \\
\hline 1 & 0,05 & 0,798 & 0,329 & Valid \\
2 & 0,05 & 0,710 & 0,329 & Valid \\
3 & 0,05 & 0,701 & 0,329 & Valid \\
4 & 0,05 & 0,580 & 0,329 & Valid \\
5 & 0,05 & 0,619 & 0,329 & Valid \\
\hline
\end{tabular}

c. Variabel desain SIA $\left(\mathrm{X}_{3}\right)$

HASIL UJI VALIDITAS VARIABEL $X_{3}$

\begin{tabular}{|c|c|c|c|c|}
\hline Item soal & $\alpha$ & $\mathrm{r}_{\text {hitung }}$ & $\mathrm{r}_{\text {tabel }}$ & Keterangan \\
\hline 1 & 0,05 & 0,504 & 0,329 & Valid \\
2 & 0,05 & 0,695 & 0,329 & Valid \\
3 & 0,05 & 0,736 & 0,329 & Valid \\
4 & 0,05 & 0,627 & 0,329 & Valid \\
5 & 0,05 & 0,706 & 0,329 & Valid \\
6 & 0,05 & 0,432 & 0,329 & Valid \\
7 & 0,05 & 0,470 & 0,329 & Valid \\
\hline
\end{tabular}

d. Variabel kinerja karyawan (Y)

HASIL UJI VALIDITAS VARIABEL Y

\begin{tabular}{|c|c|c|c|c|}
\hline Item soal & $\alpha$ & $\mathrm{r}_{\text {hitung }}$ & $\mathrm{r}_{\text {tabel }}$ & Keterangan \\
\hline 1 & 0,05 & 0,528 & 0,329 & Valid \\
2 & 0,05 & 0,400 & 0,329 & Valid \\
3 & 0,05 & 0,407 & 0,329 & Valid \\
4 & 0,05 & 0,467 & 0,329 & Valid \\
5 & 0,05 & 0,454 & 0,329 & Valid \\
6 & 0,05 & 0,385 & 0,329 & Valid \\
7 & 0,05 & 0,468 & 0,329 & Valid \\
8 & 0,05 & 0,670 & 0,329 & Valid \\
9 & 0,05 & 0,573 & 0,329 & Valid \\
10 & 0,05 & 0,648 & 0,329 & Valid \\
\hline
\end{tabular}


2. Uji Reliabilitas

HASIL UJI RELIABILITAS

\begin{tabular}{|c|c|r|l|}
\hline Item soal & Cronbach Alpha & Kriteria & Keterangan \\
\hline $\mathrm{X}_{1}$ & 0,699 & 0,6 & Reliabel \\
$\mathrm{X}_{2}$ & 0,713 & 0,6 & Reliabel \\
$\mathrm{X}_{3}$ & 0,670 & 0,6 & Reliabel \\
$\mathrm{Y}$ & 0,677 & 0,6 & Reliabel \\
\hline
\end{tabular}

\section{B. Uji Hipotesis}

1. Analisis Regresi Linier Berganda

HASIL PERHITUNGAN REGRESI

\begin{tabular}{|c|c|c|c|c|c|}
\hline \multirow[t]{2}{*}{ Model } & \multicolumn{2}{|c|}{$\begin{array}{c}\text { Unstandardized } \\
\text { Coefficients }\end{array}$} & $\begin{array}{l}\text { Standardized } \\
\text { Coefficients }\end{array}$ & \multirow[t]{2}{*}{$\mathrm{t}$} & \multirow[t]{2}{*}{ Sig. } \\
\hline & $\bar{B}$ & Std. Error & Beta & & \\
\hline (Constant) $\mathrm{X}_{1}$ & 12,625 & 4,577 & & 2,758 &, 010 \\
\hline $\mathrm{X}_{2}$ &, 414 &, 126 & & 23,287 &, 002 \\
\hline$X_{3}$ & , 454 & ,179 & & 82,539 &, 016 \\
\hline &, 389 & ,122 & & 3633,182 &, 003 \\
\hline
\end{tabular}

Hasil komputerisasi tersebut diperoleh model persamaan regresi linier berganda sebagai berikut :

$\mathrm{Y}=12,625+0,414 \mathrm{X}_{1}+0,454 \mathrm{X}_{2}+0,389 \mathrm{X}_{3}$

$\beta_{1}=$ Nilai koefisien regresi 0,414 , artinya variabel kompleksitas teknologi berpengaruh positif terhadap kinerja karyawan.

$\beta_{2}=$ Nilai koefisien regresi 0,454 , artinya variabel interdependensi berpengaruh positif terhadap kinerja karyawan.

$\beta_{3}=$ Nilai koefisien regresi 0,389 , artinya variabel desain SIA berpengaruh positif terhadap kinerja karyawan.

2. Uji F

HASIL PERHITUNGAN UJIF

\begin{tabular}{|c|c|c|c|c|c|c|}
\hline Model & $\begin{array}{l}\text { Sum of } \\
\text { Squares }\end{array}$ & DF & $\begin{array}{l}\text { Mean } \\
\text { Squiares }\end{array}$ & $\mathrm{F}$ & $\mathrm{F}_{\text {tabel }}$ & Sig. \\
\hline 1 Regression & 173.922 & 3 & 57.974 & 13.339 & 2,911 & $.000^{\mathrm{a}}$ \\
\hline Residual & 139.078 & 32 & 4.346 & & & \\
\hline Total & 313.000 & 35 & & & & \\
\hline
\end{tabular}

Hasil perhitungan di atas menunjukkan bahwa nilai hasil nilai $\mathrm{F}$ hitung sebesar 13,339 sedangkan $\mathrm{F}$ tabel mempunyai nilai sebesar 2,911, karena $\mathrm{F}$ hitung lebih besar dari $\mathrm{F}$ tabel $(13,339>2,911)$, atau dilihat dari nilai sig. $=0,000<0,05$ maka Ho ditolak sehingga dapat disimpulkan bahwa kompleksitas teknologi, interdependensi dan desain SIA secara bersama-sama berpengaruh signifikan terhadap kinerja karyawan. 
3. Uji t

HASIL PERHITUNGAN UJI $\mathrm{t}$

\begin{tabular}{|c|c|c|c|}
\hline Variabel & $\mathrm{t}_{\text {hotung }}$ & $\mathrm{t}_{\text {tabel }}$ & Sig. \\
\hline 1 (Constans) & 2,758 & & 0.010 \\
$\mathrm{X}_{1}$ & 3,287 & 2,037 & 0.002 \\
$\mathrm{X}_{2}$ & 2,539 & 2,037 & 0.016 \\
$\mathrm{X}_{3}$ & 3,182 & 2,037 & 0.003 \\
\hline
\end{tabular}

Sumber : Data primer diolah

Kesimpulan

a. Variabel kompleksitas teknologi Nilai t hitung dari hasil perhitungan model regresi pada variabel kompleksitas teknologi $\left(\mathrm{X}_{1}\right)$ adalah sebesar 3,287 lebih besar dari tabel sebesar 2,037 ( $\mathrm{t}_{\text {hitung }}=3,287$ $>t_{\text {tabel }}=2,037$ ), maka Ho ditolak berarti $X_{1}$ (kompleksitas teknologi) berpengaruh signifikan terhadap variabel $\mathrm{Y}$ (kinerja karyawan).

b. Variabel interdependensiNilai $\mathrm{t}$ hitung dari hasil perhitungan model regresi pada variabel interdependensi $\left(\mathrm{X}_{2}\right)$ adalah sebesar 2,539 lebih besar dari tabel sebesar 2,037 $\left(\mathrm{t}_{\text {hitung }}=2,539>\right.$ $\mathrm{t}_{\text {tabel }}=2,037$ ), maka Ho ditolak berarti $\mathrm{X}_{2}$ (interdependensi) berpengaruh signifikan terhadap variabel Y (kinerja karyawan).

c. Variabel desain SIA Nilai thitung dari hasil perhitungan model regresi pada variabel desain SIA $\left(\mathrm{X}_{3}\right)$ adalah sebesar 3,182 lebih besar dari tabel sebesar 2,037 ( $\mathrm{t}_{\text {hotung }}=3,182>\mathrm{t}_{\text {tabel }}=2,037$ ), maka Ho ditolak berarti $\mathrm{X}_{3}$ (desain SIA) berpengaruh signifikan terhadap variabel $\mathrm{Y}$ (kinerja karyawan).

4. Koefisien Determinasi

HASIL PERHITUNGAN KOEFISIEN DETERMINASI

\begin{tabular}{|l|c|c|c|c|}
\hline Model & $\mathrm{R}$ & $\mathrm{R}$ Squares & $\begin{array}{c}\text { Adjusted R } \\
\text { Squares }\end{array}$ & $\begin{array}{l}\text { Std.Error of } \\
\text { the estimate }\end{array}$ \\
\hline 1 & $.745^{\mathrm{a}}$ & .556 & .514 & 2.08475 \\
\hline
\end{tabular}

Sumber : Data primer diolah

Hasil perhitungan SPSS uji R di atas menunjukkan bahwa nilai adjusted $R$ Squares sebesar 0,514, ini dapat diartikan bahwa kinerja karyawan dapat dijelaskan oleh variabel kompleksitas teknologi, interdependensi dan desain SIA sebesar 51,4\% sedangkan sisanya sebesar 48,6\% (100\% - 51,4\%) dipengaruhi oleh variabel lain di luar variabel yang diteliti.

\section{Kesimpulan}

1. Dari hasil regresi linier berganda didapatkan persamaan regresi $\mathrm{Y}=12,625+0,414 \mathrm{X}_{1}+0,454 \mathrm{X}_{2}+$ $0,389 \mathrm{X}_{3}$, artinya masing-masing variabel kompleksitas teknologi, interdependensi dan desain SIA berpengaruh positif terhadap kinerja karyawan. Variabel yang paling tinggi pengaruhnya terhadap variabel kinerja karyawan adalah interdependensi karena memiliki nilai koefisien regresi paling tinggi.

2. Hasil uji F menunjukkan bahwa variabel kompleksitas teknologi, interdependensi dan desain SIA secara bersamasama berpengaruh signifikan terhadap kinerja karyawan bagian akuntansi koperasi di Surakarta.

3. Hasil uji t test menunjukkan bahwa variabel kompleksitas teknologi, interdependensi dan desain SIA secara parsial berpengaruh signifikan terhadap kinerja karyawan bagian akuntansi koperasi di Surakarta. 
4. Hasil uji $\mathrm{R}$ (koefisien determinasi) diketahui bahwa kinerja karyawan bagian akuntansi dapat dijelaskan oleh variabel kompleksitas teknologi, interdependensi dan desain SIA sebesar 51,4\% sedangkan sisanya sebesar 48,6\% (100\% - 51,4\%) dipengaruhi oleh variabel lain di luar variabel yang diteliti.

5. Dengan demikian di atas maka ipotesis dalam penelitian ini :

a. Ada pengaruh signifikan secara parsial variabel kompleksitas teknologi, interdependensi dan desain Sistem Informasi Akuntansi terhadap kinerja karyawan pada koperasi di Surakarta.(hipotesis I terbukti)

b. Ada pengaruh signifikan secara simultan variabel kompleksitas teknologi, interdependensi dan desain Sistem Informasi Akuntansi terhadap kinerja karyawan pada koperasi di Surakarta.(hipotesis II terbukti)

\section{DAFTAR PUSTAKA}

Bodnar George H., 2009, Sistem Informasi Akuntansi, Salemba Empat, Jakarta.

Bouwens, 2008, The Consequency of Customization on Management Accounting

System Design Accounting Organization an Societ, Jurnal akuntansi. Damodar. M. Gujarati, 2011, Ekonometrika Dasar, Erlangga, Jakarta.

Djarwanto PS dan pangestu Subagyo. 2010. Statistik Induktif. BPFE-UGM. Yogyakarta.

F. Anggarini, 2010, Customization, Interdependensi dan Kompleksitas Teknologi Pengaruhnya terhadap Desain Informasi Sistem Akuntansi Manajemen Perusahaan, tidak dipublikasikan UNS, Surakarta.

Gandung E, Andreas, 2008, Customization, Interdependensi, Kompleksitas Teknologi Ketidakpastian lingkungan pengaruhnya terhadap desain informasi SAM Perusahaan, Skripsi tidak dipublikasikan AUB, Surakarta.

Gatingnon, 2007, Teknologi Informasi Komputer, PT. Rajawali, Jakarta.

Ghozali Imam, 2010, Aplikasi Analisis Multivariate dengan Program SPSS, Badan Penerbit Universitas Diponegoro, Semarang.

Halim Abdul, 2010, Akuntansi Manajemen, BPFE UGM, Yogyakarta. Mangkunegara, 2012, Penilaian Kinerja Karyawan, Liberty, Yogyakarta.

Marsudi, 2011, Pengaruh faktor perubahan lingkungan orientasi teknologi dan partisipasi penyusunan anggaran terhadap desain sistem informasi akuntansi manajemen, tidak dipublikasikan, UMS, Surakarta.

RA. Supriyono, 2011, Sistem Informasi Akuntansi, Ganesha, Jakarta.

Sekaran Uma dan Mudrajad Kuncoro, 2013, Metode Penelitian Bisnis: suatu PendekatanKetrampilan Proses, Edisi 3 seri Bahasa Indonesia, Jakarta: Prehalindo.

Singarimbun Masri dan Efendy, 2010, Metodologi Penelitian, Ghalia Indonesia, Jakarta. Sugiyono, 2012, Metode Penelitian Pendidikan, Pendekatan Kuantitatif, Kualitatif, dan $R \& D$, Penerbit Alfabeta, Bandung.

Suharsimi Arikunto. 2016. Prosedur Penelitian suatu Pendekatan Praktik. Jakarta. Rineka Cipta. Jakarta.

Susanto Astrid dan Louven, 2015, Komunikasi dalam Teori dan Praktek I, Bina Cipta Bandung.

Thomson Goodhue, 2015, Organization in Action, Mc.Graw-Hill, New York.

The Liang Gie, 2017, Administrasi Perkantoran Modern, Nur Cahaya, Yogyakarta. W. Gulo, 2012, Metodologi Penelitian, PT. Grasindo, Jakarta. 